\title{
¿Ocupar o habitar? Aproximación al fenómeno actual
}

\section{Inhabitating or occupying? Approximation to the actual phenomenon}

\author{
Arq. Maritza Beatriz Granados-Manjarrés \\ Facultad de Arquitectura y Diseño, Departamento de Estética. \\ Pontificia Universidad Javeriana - Bogotá. \\ granados.m@javeriana.edu.co
}

Recibido: 11 de mayo de 2012

Aprobado: 12 de junio de 2012

\begin{abstract}
Resumen
La pregunta sobre los espacios que habitamos/ocupamos es la base sobre la cual se desarrolla el trabajo que se presenta a continuación, y esta surge de mirar con detenimiento las arquitecturas que se proyectan hoy día, en Bogotá, pero cuyo fenómeno pretende ser trasladado al ejercicio proyectual de la arquitectura en general. Primero se hace una reflexión sobre la producción formal arquitectónica, y las consecuencias de dicha producción en la experiencia espacial como un evento que debería estimular los sentidos. Las conclusiones de esta primera parte evidencian el advenimiento de un fenómeno que se caracteriza por producir todo tipo de arquitecturas, cuyo rasgo principal es la indeterminación formal, es decir arquitecturas que no parecen pertenecer a ningún lado, y por lo mismo pertenecen a todos. Segundo, se propone entender este fenómeno a la luz de la Modernidad Líquida de Bauman, para después formular el terreno desde donde se puede proyectar, en ese lugar de indeterminación en el que la arquitectura se mueve con tan aparente facilidad. Finalmente, más que conclusiones, se plantean una serie de interrogantes que podrían dar lugar a otros espacios de investigación que encuentren su derrotero en esta especulación.
\end{abstract}

Palabras Clave: crítica arquitectura, modernidad, habitabilidad, fenómeno arquitectónico, individualización.

Granados-Manjarrés, M.B. (2013): ¿Ocupar o habitar? Aproximación al fenómeno actual. Arte, Individuo y Sociedad, 25(3) 376-391

\begin{abstract}
The question about the spaces that we live in, or we occupied, is the base on which this work is developed, and this arises from carefully watching the architecture that is projected nowadays in Bogota, but whose phenomenon can be transferred to the architectonic exercise. First, a reflection is made on the architectonic formal production, and the consequences of this production in the space experience like an event that should stimulate the senses. The conclusions of this first part show a phenomenon that is characterized to produce all type of architectures, whose main characteristic is formal indetermination, that is to say architectures that do not seem to belong anywhere, and by the same belong to all. Secondly, this phenomenon can be understood from Bauman's Liquid Modernity which leads to formulate a place where it is possible to project architecture, a place that seems to be undetermined. Finally, more than conclusions, a series of questions are proposed to become spaces of investigation that could find its map course in this speculation.
\end{abstract}

Key Words: architectonic critique, modernity, inhabitability, architectonic phenomenon, individualization. 
Granados-Manjarrés, M.B. (2013): Inhabitating or occupying? Approximation to the actual phenomenon. Arte, Individuo y Sociedad, 25(3) 376-391

Sumario: 1. Introducción, 2. El estremecimiento, 3. Arquitectura hoy, 4. Proyectar desde la crisis, 5. Conclusiones. Referencias.

\section{Introducción}

¿Qué habitamos? Está claro que ésta es una pregunta inherente a nuestra condición de arquitectos. La reflexión surge sobre los espacios que habitamos, pero imagine usted que la respuesta puede ser 'nada, no habita usted nada', y todo porque aparentemente, ocupamos, ya no habitamos.

La aproximación que tiene lugar en este trabajo gira en torno a un interés fundamental de comprender el fenómeno que se fragua en la contemporaneidad a propósito de los espacios que habitamos versus el acto elemental de ocupar el espacio. En búsqueda de una claridad sobre los términos utilizados, se hizo una exploración no exhaustiva de aquello que es entendido como habitabilidad, y en términos generales tiene que ver con las condiciones básicas de confort que debe tener un espacio, es decir, "La obtención de condiciones adecuadas para la permanencia de las personas en un lugar y para el desarrollo satisfactorio de las actividades propias de su permanencia" ${ }^{\text {, }}$, esto en palabras de Alberto Saldarriaga, quien daría su definición hace, al menos, 30 años. Sin embargo esta definición no parece ser suficiente, ya no es más un acto de "obtener condiciones adecuadas", sino más bien de promover actos perceptivos al interior de los espacios. Esto quiere decir que el ejercicio proyectual debe pensarse como un acto inseparable de quien habita, es decir no para él sino desde él, lo que garantiza que los espacios se vinculen profundamente con el usuario. La arquitectura y su consecuente habitabilidad debe ser abordada como ser biológico dotado de características propias y no solamente como un contenedor que cumple condiciones de confort. $\mathrm{Al}$ margen de la dureza de sus límites físicos es claro que la arquitectura tiene capacidades definitivas de mutación que siempre responden a la forma en que se habita.

Dicho esto, la definición que más se acerca a esta nueva habitabilidad tal vez tenga que ver con la reflexión y apropiación de paradigmas contemporáneos y, como define Iliana Hernández, en su texto Estética de la habitabilidad y nuevas tecnologías, el concepto de habitabilidad debe ser entendido como "el que vincula el pensamiento creativo con una manera particular de relacionarse con el individuo y con su entrono (...) se define allí más por los comportamientos y maneras de vida generados por la forma como nos relacionamos con la información: ubicuidad, instantaneidad e inmediatez, que por la forma o el tipo de espacio para habitar"2.

Por otro lado, ocupar es entendido como la consecuencia de concebir espacios indeterminados, es decir, como el mero acto de hacer uso de un espacio que a falta de articulación conceptual y espacial no deja otra opción que la posibilidad de ser utilizado, pero no promueve ningún tipo de acto perceptivo.

En este orden de ideas se desarrolla a continuación toda una especulación que intenta dar luces del porqué de nuestros productos arquitectónicos, e intenta proponer un camino para abordar este fenómeno en el que nos situamos. 
A una ciudad que requiere tantos artefactos urgentes -como 'una casa para cada uno', escuelas, transportes- no le interesa que se coloquen guindas de pastel sobre sus desastres.

- Paulo Mendes da Rocha. Pritzker 2006-

Un caballo pintado a rayas no es una cebra.

- Louis Kahn

Remedos de arquitectura, espacios frívolos y disonantes se alzan indistintamente. La ciudad se construye con retazos y sobrantes de arquitecturas mal pensadas que, seguramente, no tienen otro propósito que despertar intereses económicos o comerciales, y aun así estas inquietudes no parecen tener mucha relevancia, ni siquiera para la mayoría de arquitectos. Es hora de preguntarse entonces, ¿estamos acaso condenados a no vivir la arquitectura? Y si eso es así, ¿qué estamos habitando? ¿Qué es eso que se levanta y configura la ciudad con la que diariamente convivimos?

Rem Koolhaas afirma que en la modernidad, y consecuentemente en la posmodernidad, el producto construido no es la arquitectura moderna sino el espacio basura.

El espacio basura es la suma total de nuestro éxito actual; hemos construido más que todas las generaciones anteriores juntas, pero en cierto modo no se nos recordará a esa misma escala (...) Nuestra preocupación por las masas nos ha impedido ver la arquitectura de las personas. El espacio basura parece una aberración, pero es la esencia, lo principal...el fruto de un encuentro entre la escalera mecánica y el aire acondicionado, concebido en una incubadora de pladur (las tres cosas faltan en los libros de historia). (Koolhaas, 2007, p. 7,8)

A la luz de esta afirmación, parece tener sentido eso tan obvio en nuestras ciudades latinoamericanas, somos la adición desmesurada de intentos de configurar espacios. Nuestras ciudades se alzan pretenciosas tratando de asemejarse a toda costa a ciudades cuya historia, no solo difiere de la nuestra, sino que además nos aventaja por varios siglos. No parece haber, ni tendría por que, una arquitectura latinoamericana original, y sin embargo ese no es exactamente el problema. Más bien, pareciera que los arquitectos en nuestro afán por hacer más por el usuario, lo olvidamos. Lo dejamos en el camino.

Sumado a esto, empiezan a aparecer fenómenos que en brazos de la globalización parecen coherentes pero que si se miran con detenimiento no son consecuentes con las ciudades que vivimos. Hace poco surgió una reflexión sobre la aparición de un centro comercial en la zona rosa bogotana, un sector de la ciudad que sufre de un excesivo comercio, que entre Dior y Dolce \& Gabbana, forja un velo que pretende cubrir las ya atenuadas diferencias sociales que vive este país. Un sector de 2 hectáreas que sirve al $15 \%$ de la población bogotana que se encuentra entre los estratos 4 y 6 (medio, 
medio-alto y alto) y donde el alquiler por metro cuadrado es de cerca de U\$7500 mensuales, lo que equivale a 23 salarios mínimos. 16 manzanas en las que de ese $15 \%$ solamente un $4 \%$ tiene capacidad real de compra.

Sin embargo, hace 9 años, a alguien se le ocurrió que era necesario un centro comercial (Fig. 1) más, y naturalmente se importó la mejor arquitectura disponible en materia de malls, que como resultado alumbró un espacio empalagoso y huero, que está sentenciado a vivir en el exceso de su condición alienígena. El emprendimiento fue encargado a una compañía norteamericana que se precia de crear proyectos armoniosos e integrados con su entorno cultural, afirmación que no podría estar más lejos de la verdad. El advenedizo producto es un mall de 4 pisos, remedo de la arquitectura miamense de principios de siglo XX, que utiliza todos los ornamentos existentes en el Miami Art Deco y el Mediterranean Revival, sin aparente mesura. Es ahí donde reside la crítica, no en las nuevas intervenciones, que como arquitectos celebramos, sino en la aparición de arquitecturas ajenas y fortuitas que no llegan solas, sino que lo hacen cargadas de una historia que a todas luces disuena con su anfitrión. Así que no solo olvidamos al usuario, también olvidamos el territorio.

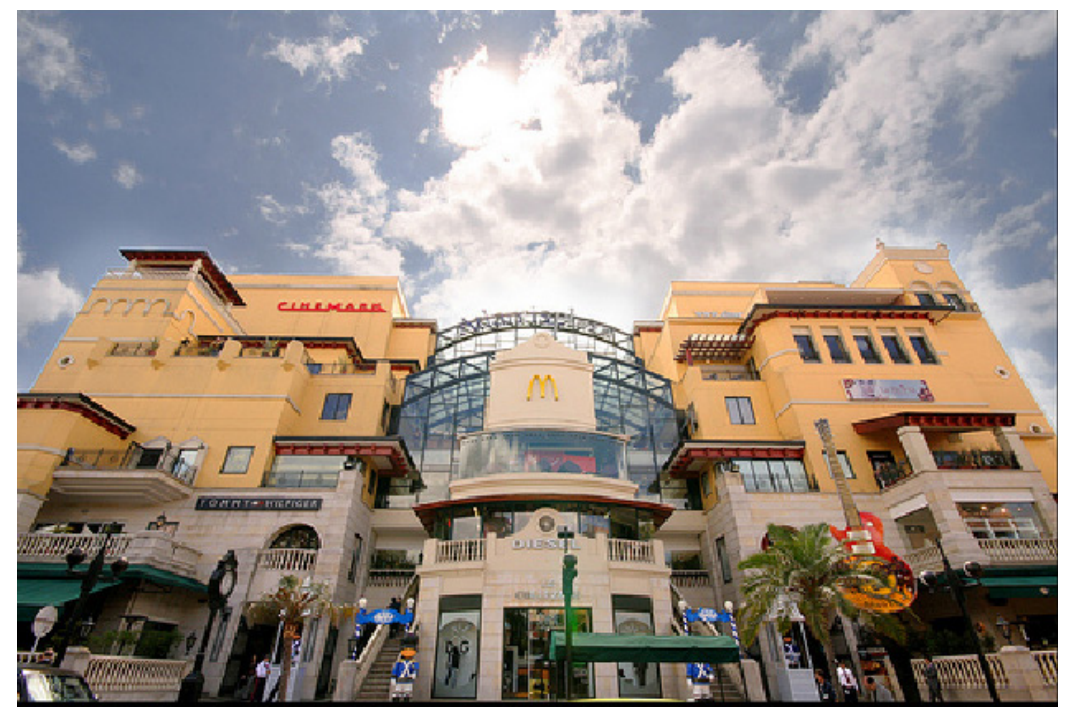

Figura 1. Centro Comercial Atlantis Plaza. Fotografía de: Hansa Tours - Colombia Travel@

No obstante estos olvidos nos están saliendo caros. No sólo porque la evidente falta de argumentos formales para hacer arquitectura habla muy mal de nuestro quehacer sino porque cada vez hay menos oportunidad de gozar del estremecimiento y excitación que causa un espacio bien concebido. Nos lo negamos como arquitectos, $\mathrm{y}$ en consecuencia se lo negamos al mundo. 


\section{El estremecimiento}

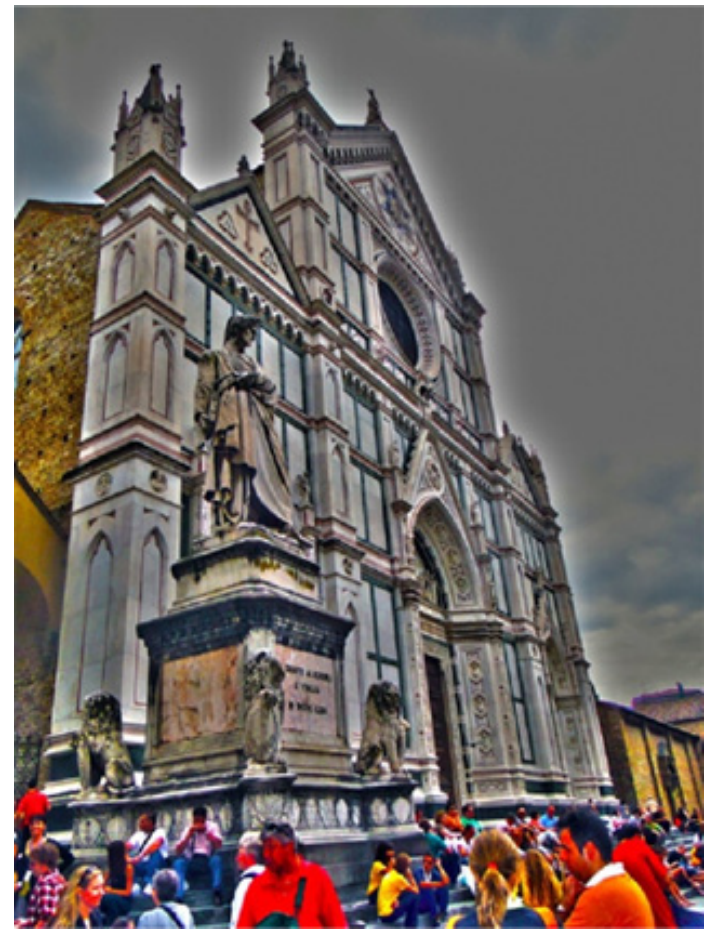

Figura 2. Santa Cruz de Florencia. Fotografía de: Rodrigo Soldon (C)

En 1917 el novelista francés Marie-Henri Beyle, más conocido como Stendhal, describió en su libro Nápoles y Florencia: Un viaje de Milán a Reggio, su experiencia al visitar la Basílica de Santa Cruz de Florencia (Fig. 2): "En una especie de éxtasis por la idea de estar en Florencia (...). Absorto en la contemplación de la belleza sublime, la veía de cerca, la tocaba por decirlo así. Había llegado a ese punto de emoción en el que convergen las sensaciones celestes provocadas por las bellas artes y los sentimientos apasionados" 3

Junto con esta descripción aparecían nombrados una serie de síntomas como vértigo, temblor, sensación de pánico y despersonalización, un cuadro semipatológico que recibió el nombre de Síndrome de Stendhal, y que fue acuñado y detallado por la psiquiatra italiana Graziella Magherini en 1989, en un libro del mismo nombre que señala las consecuencias que puede causar enfrentarse a la belleza. "La Medicina Psicosomática arguye que este Síndrome obedece a una etiología muy especial: la saturación de la capacidad humana para recibir, en poco tiempo, impresiones de gran belleza artística"4

Tal parece que esa saturación es cada vez más difícil de encontrar en nuestra arquitectura, al menos la contemporánea. Evidentemente existen ejemplos de buena 
arquitectura hoy día, sobre todo si nos ceñimos a algunos de los productos del Star System, sin embargo ese sistema todavía no se hace presente en la mayoría de ciudades, y menos latinoamericanas donde es claro que no hay medios económicos para solventar tales constelaciones. No obstante, bajos presupuestos no justifican pobres intervenciones.

E1 26 de diciembre de 2004 un tsunami arrasó con Kirinda, una pequeña población de pescadores, ubicada en el suroeste de Sri Lanka, donde cerca de 120000 casas tuvieron que ser reconstruidas. El arquitecto japonés Shigeru Ban hizo parte de un proyecto de rehabilitación que incluía la construcción de 67 casas, una mezquita y un plantío, que por la naturaleza del proyecto contaba con muy bajo presupuesto, y el período de construcción debía ser reducido. El material escogido fue la tapia pisada, que está disponible en Sri Lanka, por muy bajo costo, y además no necesita albañiles capacitados (Fig. 3, 4, 5). Cada casa tiene dos habitaciones y un espacio semi-abierto techado que juega un importante papel en la vida de los habitantes, pues es el espacio utilizado para las comidas familiares, la socialización con los vecinos y el trabajo con sus redes y elementos de pesca.

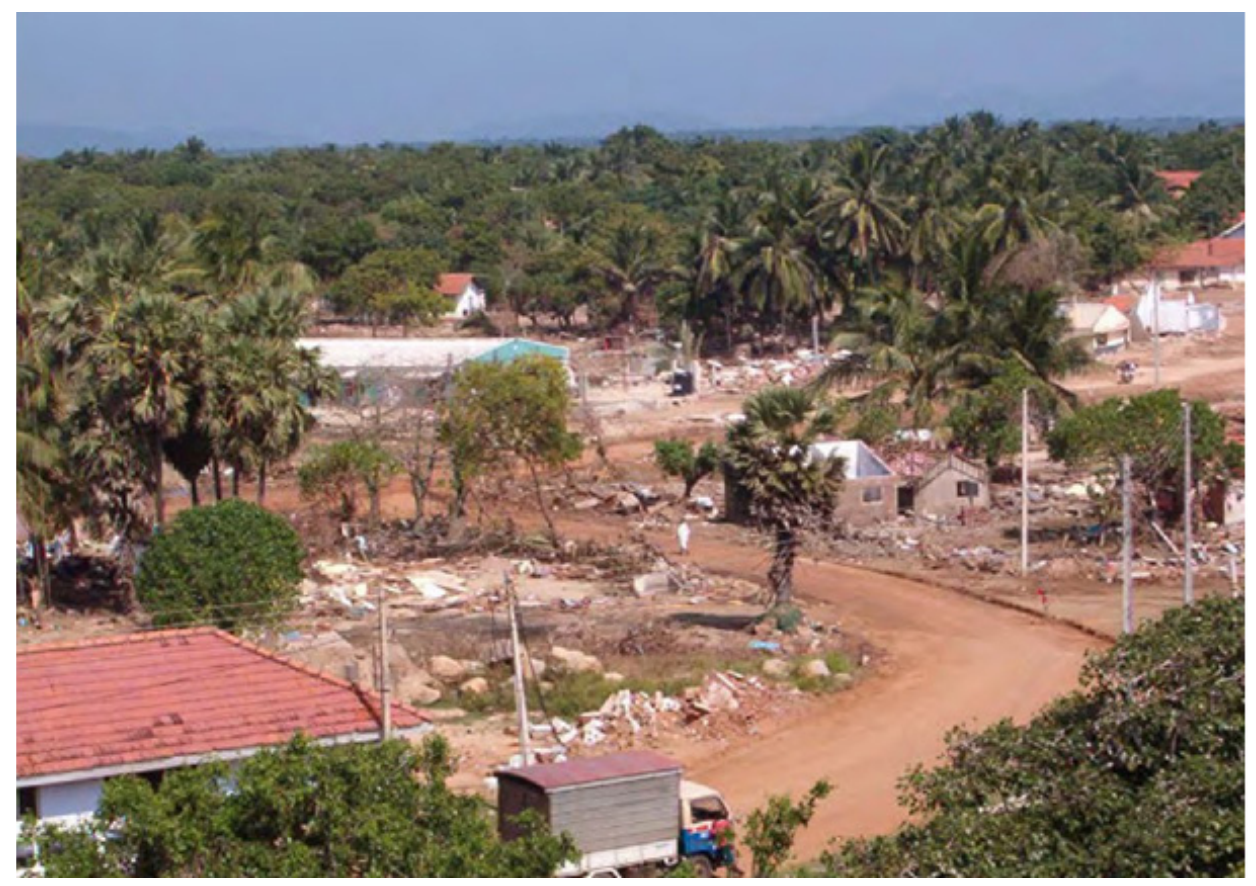

Figura 3. Vista de Kirinda después del Tsunami. Fotografía de: Shigeru Ban Architects (C) 


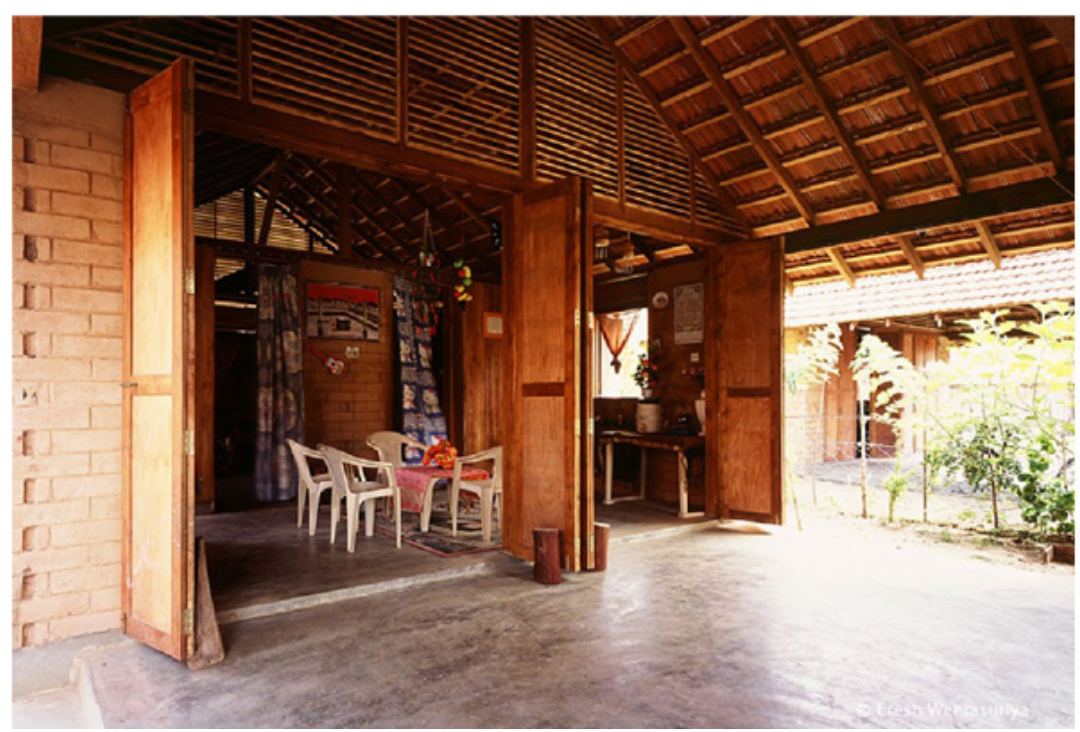

Figura 4. Vista del porche. Fotografía de: Eresh Weerasuriya. (C)

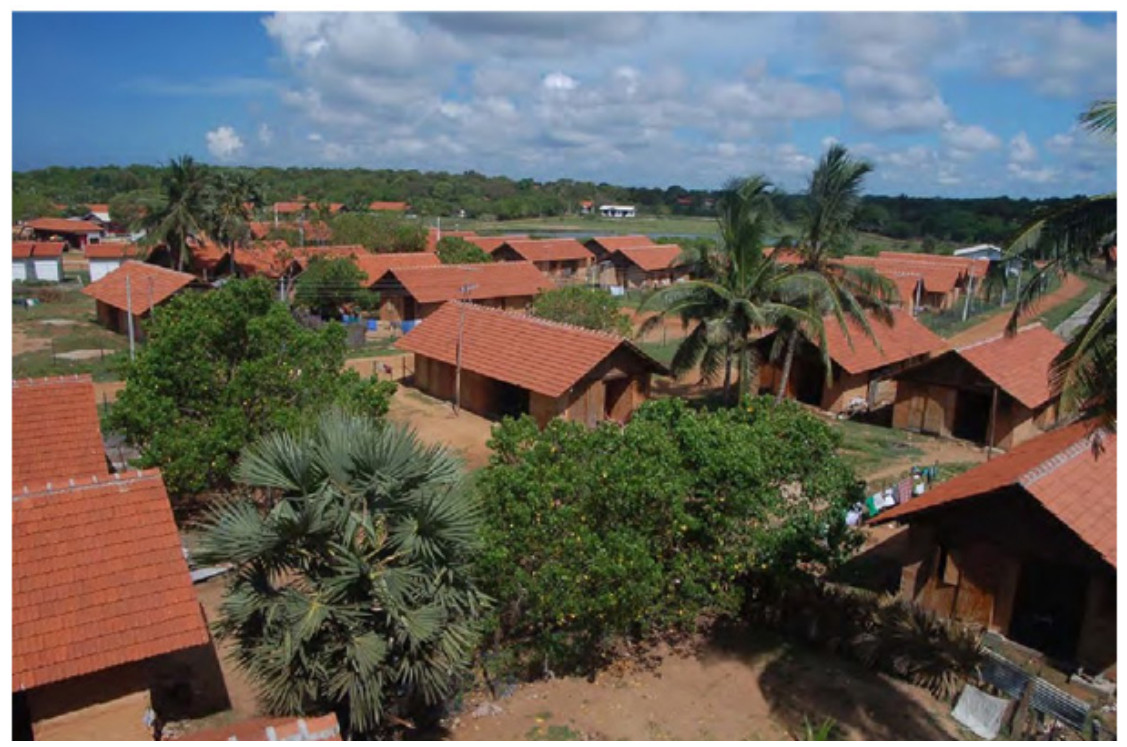

Figura 5. Vista de Kirinda después de la reconstrucción. Fotografía de: Shigeru Ban Architects. (C)

Por su parte, la Escuela de Arquitectura de la Universidad de Yale incorporó, desde 1967, en su plan de estudios para primer año, la oportunidad de diseñar y construir una estructura como parte de su educación. Durante los 45 años que lleva este proyecto, que ahora se conoce como Vlock Building Project, el bajo presupuesto ha sido una constante pues se espera que los estudiantes adquieran un compromiso 
social con poblaciones más necesitadas o en situaciones de pobreza. Naturalmente el proyecto se ha convertido en piedra angular del proyecto educativo de esta escuela de arquitectura pues enfatiza en el significado de la arquitectura como contribución social, diálogo y forma construida, al punto que a mediados de 2007 se hizo una publicación ${ }^{5}$ que documenta cada uno de los proyectos, situando el programa en su contexto histórico ${ }^{6}$. Ejemplos de este tipo de intervenciones hay muchos. Queda claro entonces, que no es un problema del presupuesto, sigue siendo un problema del arquitecto.

\section{Arquitectura hoy}

Ahora, el olvido del usuario, del territorio y esa cada vez más común incapacidad de proyectar espacios consecuentes y propositivos, puede situarse dentro de lo que Zygmunt Bauman propone como Modernidad Líquida.

Bauman encuentra el calificativo para denominar la época actual como "líquida" y (...) este adjetivo indica la imposibilidad de mantener su forma; contraponiéndola así con una etapa previa y "solida". De tal forma, la metáfora de la fluidez le es útil para tipificar la sociedad actual ya que los líquidos "...no se fijan en el espacio ni se atan al tiempo" (Bauman, 2003b: 8), sino que se desparraman y, por sobre todas las cosas, triunfan sobe los sólidos. (Fernández, Marta (Comp.), 2006, p. 65).

Para Bauman esta modernidad nuestra fluye con la facilidad con que fluyen los líquidos, y no intenta catalogarla como posmodernidad pues, según él, la posmodernidad indica el final de la modernidad y somos tan modernos como siempre. Por otro lado, tampoco puede incluirla en la "modernidad tardía" de Giddens, o en la "segunda modernidad" de Becks, así que propone esta alternativa "como época fluida y móvil donde predominan el desarraigo y la desterritorialización"”, y en una cultura donde la velocidad solo parece escalar posiciones, la liviandad nos hace ver que entre menos cargados estemos, más rápido avanzamos.

Bauman afirma que la solidez que está siendo sometida a la disolución es la que vincula las elecciones individuales y los proyectos y acciones colectivos, y hace una referencia a las "instituciones zombis" propuestas por Ulrich Beck en una entrevista en 1999, que las define como aquellas que están vivas y muertas a la vez, es decir, Beck propone que no podemos aferrarnos a categorías tradicionales de familia, vecindario, Estado o Nación, porque es aferrarse a términos que están muertos en vida, y estos zombis son producto de la individualización que estamos viviendo.

El ejemplo que mejor lo explica es el concepto de familia. Beck se pregunta ¿Qué es la familia hoy día? ¿Qué significa? "La paternidad, el centro de la familia, se ha empezado de desintegrar bajo el concepto de divorcio. Las familias pueden ser constelaciones de muy diferentes relaciones (...) Si usted pregunta que es la familia, la respuesta hace 20 años era muy clara. Hoy día no hay una respuesta simple. Puede estar definida como un lugar geográfico, una unidad económica donde los individuos dependen de otros, o como una unidad social de individuos que quieren vivir juntos, y claro todas estas definiciones se pueden contradecir (...)"\$

Desde esta óptica y sumado a la propuesta de Bauman, es la individualización el 
detonante de los cambios en nuestra modernidad, así que surge la pregunta ¿será que la arquitectura tradicional se está convirtiendo en uno de estos zombis que ya no responden al momento histórico que vivimos? De ser así, ahí podría estar la respuesta a porque el abandono de todo lo que fundó la arquitectura tradicional. Esto podría significar que al hacer uso de conceptos que ya no nos pertenecen no puede haber otro producto que propuestas yertas, y además en el proceso de individualización tan propio de la modernidad líquida, también como arquitectos individualizamos las propuestas, lo que claramente afecta al usuario. El mundo es de los individuos, ya no más de las sociedades, ni de los grupos. Entonces ¿qué es lo que ocupamos? Pues a la luz de esta reflexión aparentemente ocupamos espacios que se debaten entre la vida y la muerte, tal como en el ejemplo de la familia, hace 20 años el concepto de casa, museo o biblioteca era mucho más claro, ahora puede estar definido por una serie de conceptos tan distintos como individuos hay, y claramente tan inestables como cualquier líquido.

El hecho de que la estructura sistémica se haya vuelto remota e inalcanzable, combinado con el estado fluido y desestructurado del encuadre de la política de vida, ha cambiado la condición humana de modo radical y exige repensar los viejos conceptos que solían enmarcar su discurso narrativo. Como zombis, esos conceptos están hoy vivos y muertos al mismo tiempo. La pregunta es si su resurrección -aun en una nueva forma o encarnación- es factible; o, si no lo es, cómo disponer para ellos un funeral y una sepultura decentes. (Bauman, Zygmunt, 2002, 13-14).

\section{Proyectar desde la crisis}

Ahora, a la luz de esta reflexión parece evidente que asistimos a la agonía de la arquitectura tal y como la conocemos, pero en palabras de Peter Eisenman los cambios que dan paso a las transformaciones de una disciplina deben empezar en alguna parte, y que mejor que esta fisura por donde se filtran tan diversos productos formales. Aparece entonces el terreno perfecto para repensar la arquitectura. Un terreno que se funda en la ruptura de los cánones y en todo aquello que deviene con la modernidad, y aunque, como propone Tafuri, está claro que esta arquitectura del siglo XX no puede ser leída en forma lineal sino "como una experiencia pluriforme, compleja, en la que es lícito seccionar en diversas direcciones recorridos no sólo de arriba abajo, del comienzo al fin, sino también transversales, oblicuos o en diagonal"9, hay un fenómeno que es común a la forma en que se está pensando la arquitectura, sobre todo la latinoamericana.

En este sentido, diríamos que, no solo asistimos a la agonía de la arquitectura sino que nos situamos en ella, estamos de pie en el límite, en el quiebre, en el pliegue que resulta de plisar nuestro momento histórico. Proyectamos desde la inestabilidad inherente al filo en que intentamos apoyarnos, así que resulta natural que nuestras arquitecturas sean tan vertiginosas. Se producen arquitecturas casi por sí solas, urgidas de ser proyectadas y alumbradas, de ocupar un lugar en el borde y por un momento resonar profusamente en los desdibujados límites que la contienen. Ahora, 
es propio que de esta inestabilidad surjan proyectos de toda índole, entre buenos y malos, unos acertados y otros no tanto como la natural adecuación del quehacer a los nuevos paradigmas, así que mientras el líquido se estabiliza nos moveremos entre habitar y ocupar, entre vida y muerte hasta que por fin encontremos un suelo estable donde asentarnos y si no es estable al menos estaremos más preparados para sus alteraciones.

En el libro Diferencias topográficas de la arquitectura contemporánea, De SolàMorales afirma que "nuestro tiempo carece de un sistema claro de valores en cuya vigencia haya suficiente acuerdo colectivo como para que sirva de fundamento de las actividades prácticas, tales como la producción artística y arquitectónica, las cuales son siempre la manifestación sensible de las ideas dominantes en el seno de una civilización" ${ }^{\prime 10}$. Sin embargo, se da a la tarea de indagar cómo pueden fundarse obras de arte con un significado profundo en una situación de crisis como la que estamos viviendo, donde la diversidad y el contraste son avasalladoras, es decir, intenta proponer un análisis que lleve a propuestas arquitectónicas que no solamente se aboquen a la producción edilicia sino que construyan sentido, muy a pesar de la debilidad conceptual en la que nos encontramos donde valores y referentes derivan en la dispersión. Todo esto, da como resultado que el ejercicio proyectual y su consecuente maduración no se haga como expresión de un proyecto colectivo que sea coherente y unitario sino que impulsa la aparición de discursos particulares que, aun cuando deberían fundarse como experiencias privadas, se exponen con vehemencia al público.

lAl final del siglo XX, rota la confianza en el progreso científico-técnico y en los valores del sujeto, el arte y la arquitectura se presentan desde su desolación, desde su ausencia de solar, sólo justificados desde la experiencia y las proposiciones del sujeto empírico, sensible testimonio de la perdida de la totalidad, sólo capaz de transmitir desde la frágil limitación de sus condiciones, contenidos relativos, parciales, individuales (De Solà- Morales, Ignasi, 2003, p. 120),

Una vez más nos encontramos de frente con la individualización de Beck. En el prefacio que hace Scott Lash del texto La Individualización, habla de la aparición del 'individualismo no-lineal', donde este individuo de la segunda modernidad, no está determinado por la máxima de Descartes "pienso luego existo", sino más bien, en términos de "existo", es decir con la capacidad de "hacerse individuo" y no solo de "serlo". En palabras de Beck, esto quiere decir que el sujeto contemporáneo está caracterizado por la elección, donde generaciones pasadas no tuvieron dicha oportunidad. Sin embargo, esas elecciones deben hacerse con rapidez, no hay tiempo para hacerlo de otro modo, y en consecuencia tampoco hay mucho tiempo para tomar distancia y reflexionar, y así construir biografías lineales. Entonces este sujeto contemporáneo debe resignarse a tener biografías de bricolaje. En resumen, el 'individualismo no-lineal' es la consecuencia del repliegue de las instituciones clásicas, donde los sistemas lineales han sido quebrantados. Sin embargo, el sujeto no desaparece, ni tampoco el conocimiento, solo qué éste es un conocimiento de incertidumbre, donde no hay normas claras, ni vigentes. 
Vivimos en una era de riesgo que es global, individualista y más moral de lo que suponemos. La ética de la autorrealización y logro individual es la corriente más poderosa de la sociedad occidental moderna. Elegir, decidir y configurar individuos que aspiran a ser autores de su vida, creadores de su identidad, son las características centrales de nuestra era (...) Pero cualquier intento de crear un nuevo sentido de cohesión social tiene que partir del reconocimiento de que la individualización, la diversidad y el escepticismo están inscritos en nuestra cultura. (Beck, Ulrich. 2002, 13).

En resumen, presenciamos dos fenómenos que resultan ser absolutamente dependientes, y que cuando son trasladados a la arquitectura parecen tener mucho sentido. Por un lado está la crisis de los sistemas clásicos, los cánones y la inestabilidad del discurso arquitectónico; y por el otro, y como consecuencia de esto, aparece la individualización del arquitecto que está en la búsqueda de satisfacer sus propios intereses, con la intención de "hacerse arquitecto" y no solo "serlo", es decir aparece la intención de no solo limitarse al quehacer, sino de proponer un discurso y un sentido que genere reflexiones e incertidumbres.

$\mathrm{Y}$, ¿qué si realmente llegamos al fin de la arquitectura, al menos momentáneamente? Supongamos que, como se expuso anteriormente, la arquitectura está agonizando ¿cuáles son las consecuencias? Tomando la propuesta que hace Arthur Danto en la introducción de su libro Después del fin del arte, podríamos pensar que en la búsqueda de nuevos cánones arquitectónicos, el tema central de la arquitectura es ella misma, es decir que la reflexión que se hace sobre la arquitectura no pretende producirla sino más bien conocerla. Posiblemente suceda en la arquitectura lo que en su momento sucedió con el arte, y se trata de la aparición de la pregunta filosófica sobre cuál es su naturaleza. En este momento los arquitectos estamos descubriendo que los límites son extremadamente flexibles, esta contemporaneidad nuestra es "desde cierta perspectiva, un período de información desordenada, una condición casi perfecta de entropía estética, equiparable a un periodo de casi perfecta libertad. Hoy ya no existe más ese linde con la historia. Todo está permitido."11

Pero, de ser así ¿qué sigue? Se proponen dos procesos paralelos y complementarios: el primero que tendrá que ver con la pregunta filosófica sobre la arquitectura y la naturaleza de esta a la luz de la flexibilidad que le es permitida, pues se hace necesaria la maduración de la reflexión arquitectónica, que si bien recién se está consolidando, en este contexto contemporáneo, es fundamental; en palabras de Solà-Morales "el discurso de los arquitectos sobre la arquitectura no es todavía un juicio crítico, no es la confrontación global en la que consiste la cultura pero es una voz necesaria, tan imprescindible como la de cualquier otro agente cultural que quiera intervenir en la construcción del sentido". ${ }^{12}$

El segundo, que se espera se alimente de aquel discurso, se enmarcará en la búsqueda, proyección y construcción de eventos arquitectónicos que puedan empezar a consolidar aquello que será la arquitectura que nos defina en el futuro, y nos sitúe en la historia, con la aparición de nuevos cánones y paradigmas.

A propósito de los cánones, Peter Eisenman escribe un libro que condensa diez edificios que a su juicio son canónicos definiéndolos así: "Una obra canónica es una bisagra, una ruptura; en otras palabras, una premonición de algo que necesariamente señala un cambio". ${ }^{13}$ Es a esta definición a donde deberíamos estar apuntando, 
es decir, que aquello que está señalando el cambio no lo haga por su falta de argumentación formal sino por el contrario, por su claridad en ella. Sentimientos sublimes deberían fraguarse con la aparición y cristalización de nuevas arquitecturas, no solo conformarse con invadir el territorio, sino encontrar su lugar en él.

Ahora, Eisenman aborda el término de canon a partir de la obra de Harold Bloom El Canon Occidental, donde este es entendido como "una experiencia de los límites, que están ampliados o rotos, o que son vitales, originales arbitrarios y personales"14. Pero, ¿por qué un canon? Para Eisenman si la historia habla del método, el arquitecto y la época, el canon habla de lo textual, lo fenomenológico y lo representativo, es decir de todo aquello que está presente en la obra pero que no se ve.

En cada uno de los casos, los edificios que aquí se presentan disturban la complacencia del acto de la lectura. (...) Estos edificios no sólo desafían las convenciones formales y conceptuales sedimentadas en la historia de la lectura en detalle, sino que también desafian aquello que constituye las persistencias de cualquier arquitectura: la relación de la parte con el todo, la distinción sujeto/objeto, las coordenadas cartesianas y la díada abstracción/movimiento moderno (Eisenman, Peter. 2011, p. 24).

Para Eisenman la lectura en detalle tiene que ver con la capacidad de ver las ideas implícitas en una obra arquitectónica, es decir con la capacidad no de ver con los ojos sino de ver con la mente, y es esta lectura es la que debe surgir de aquello que se proponga, de modo que su producción formal implique el análisis de ideas críticas en la arquitectura. Entonces, tal y como se propone se buscan edificios transgresores, que pongan en duda las obras anteriores a él, e incertidumbre en aquellas que la sucedan, y que tengan la capacidad de cuestionar toda suerte de problemas arquitectónicos hasta que la grieta sea tan grande que no tengamos más opción que rendir tributo a los cánones que se funden y empecemos a proyectar desde otros escenarios.

Vale la pena aclarar que no se pretende uniformizar la ciudad, y mucho menos los gustos, ni se aspira a que todos los proyectos provoquen los síntomas descritos por el Síndrome de Stendhal, pues está claro que para que la crítica tenga lugar esta tiene que provocar varias lecturas. La propuesta es que aún cuando el producto sea sujeto de odios y amores éste en sí mismo pueda argumentarse como resultado, es decir, que tenga suficientes herramientas durante su concepción como para que tenga fundamentos precisos para defenderse y no se desplome fácilmente. Esto quiere decir, siguiendo a Eisenman, que es deseable que aparezcan eventos que presenten lecturas alternativas y promuevan la crítica de la arquitectura, en un escenario distinto al de la historia, porque este en sí mismo no proporciona el marco ideal para que la crítica se dé.

\section{Conclusiones}

¿Cómo se concluye en medio de tanta incertidumbre? Más que conclusiones, esta reflexión solo deja preguntas y arroja dudas importantes a propósito de nuestro quehacer en la arquitectura. Por un lado es importante preguntarse sobre el papel de la identidad y la apropiación de estas arquitecturas que proyectamos que pueden ser tan insulsas como variadas. ¿Será que estos dos conceptos también son zombis que 
necesitan revisión?, sin embargo ¿Por qué despiertan arraigos? ¿Será posible que los despierten solo porque no dejamos otra opción? En un contexto en el que la velocidad tiene tanta vigencia ¿todavía tenemos tiempo de arraigarnos?

Pero, ¿por qué nuestra arquitectura es lo que es? Entendiendo la época arquitectónica como un momento donde la arquitectura supera a los arquitectos, es decir, que pensar en arquitectura emerge en diversas situaciones, Pablo Sztulwark afirma que asistimos a una época no arquitectónica o post-arquitectónica.

Junto con Ignacio Lewkowicz, escriben un texto que se da a la tarea de encontrar ese plus que alimenta el discurso arquitectónico, pues consideran que la arquitectura no puede ser solamente por sí misma, y llegan a una conclusión que aparece en el texto casi de forma desprevenida, pero cuya potencia es innegable: "La arquitectura es una actividad que humaniza el espacio"15, y esta humanización tiene que ver no solo con la apropiación del espacio, sino también con la capacidad de convertir el espacio en mundo, un mundo habitable y con sentido.

A la luz de esta definición y de la especulación que la precede se llega nuevamente a pensar que la clave está en el usuario.

La arquitectura debería ser sujeto, habitante.

Sin embargo, por el momento, la arquitectura es para los arquitectos. Esta reflexión tiene su origen y posiblemente su solución al interior de la academia, la práctica y el oficio de la arquitectura. Es muy probable que quien la habita ni siquiera sospeche en donde lo estamos situando, ni que tampoco vislumbre que está siendo privado de grandes experiencias arquitectónicas, mientras nosotros terminamos de entender cómo se proyecta en la contemporaneidad, aturdidos con tanta información. Es necesario que entendamos el lugar en el que estamos, la oportunidad que se nos presenta, porque finalmente quienes en el habitar construyen sentido son los habitantes, y es nuestra responsabilidad que dicha construcción sea tan legítima como sea posible.

A este respecto Fredric Jameson hace un análisis de la situación actual a manos de dicho habitante arguyendo que no estamos preparados para el cambio urbano que estamos viviendo, es decir, "se ha producido una mutación en el objeto, e incluso ha sido acompañada por la mutación equivalente del sujeto; pero aún no estamos en posesión de las herramientas perceptivas correspondientes a este nuevo hiperespacio (...) se nos aparece como un imperativo que ordena el nacimiento de órganos nuevos, la ampliación de nuestra sensibilidad y de nuestro cuerpo hasta unas dimensiones nuevas, por el momentos inimaginables y quizás en última instancia imposibles" ${ }^{\prime 16}$. En resumen esta arquitectura nuestra es ajena al habitante, a diferencia de la arquitectura que nos precedió, cuyo objetivo pasaba por el usuario. Es esto lo que Sztulwark define como época no arquitectónica, esa subjetividad desde donde se proyecta, que él la enmarca en la arquitectura del espectáculo de Quetglas, es decir la arquitectura que es del objeto, no del sujeto. "Como lo piensa Nicolás Bourriaud: la obra genera lazo y da de que hablar. Ahora, si el contemplador no se constituye, la obra tampoco"17. En definitiva, nos encontramos en el quiebre de nuestra labor. No sabemos como proyectar y sin esto se dificulta relacionar al sujeto con el producto arquitectónico. Sin sujeto no hay experiencia y sin esta, no hay lugar. Una vez más la propuesta es proyectar con quien habita, para él, sin reducirlo a un uso, sin convertirlo en un 
simple usuario.

Esto es un llamado a nuestro quehacer porque parece absolutamente necesaria la revisión del concepto de arquitectura ¿Qué proponemos y desde dónde? ¿Qué resultados daría la arquitectura si fuera abordada desde la individualización? Está abierto el espacio de reflexión y construcción, para que surjan respuestas, críticas y debates con la esperanza de que pronto podamos ver como emerge, se sitúa y crece una nueva arquitectura.

(...) la tarea es seguir teorizando lo más al pie posible de la práctica arquitectónica; la tarea es seguir teorizando como insumo de la práctica arquitectónica: no al pie para explicar sino al pie para reconducir el pensamiento sobre la propia práctica. Así, el espacio de teorización en arquitectura no es la mera explicitación en palabras de la teoría que implícitamente está materializada en los proyectos y las obras, sino el requerimiento de una interacción permanente entre la teoría pensada como teoría y la práctica teorizada como práctica; la teoría como insumo de la práctica y la práctica como sitio de experiencia de surgimiento de la teoría. Es decir, teorizar en arquitectura es agilizar el circuito entre la cabeza y las manos, es operar de modo que ese circuito no esté supuesto sino puesto efectivamente a trabajar (Lewkowicz Ignacio y Sztulwark, Pablo. 2003, p. 11, 12).

\section{Referencias}

Bauman, Z. (2002). Liquid Modernity. Cambridge: Polity Press.

Beck, U. (2002). La Sociedad Del Riesgo Global. Madrid: Siglo XXI.

Beck, U. y Beck-Gernsheim, E. (2003). Individualization. Londres: Sage Publications.

Bloom, H. (2004). El canon occidental la escuela y los libros de todas las épocas. Barcelona: Anagrama.

Cruz, J (2001). La Gioconda Desde Una Visión Histórica Y Médica (Hipótesis Patológicas En Su Pintura). Anales De La Real Academia Nacional De Medicina. Tomo CXVIII (4): 807-830

Danto, A. (1999). Después del fin del arte: el arte contemporáneo y el linde de la historia. Barcelona: Ediciones Paidós Ibérica.

De Solà-Morales, I. (2003). Diferencias. Topografia de la arquitectura contemporánea. Barcelona: Gustavo Gili.

Eisenman, P. (2011) Diez Edificios Canónicos. 1950 - 2000. Barcelona: Gustavo Gili.

Fernández, M. (2006). Zygmunt Bauman (1925). Diagnóstico sociológico en nuestro tiempo. En Fernández, M. (Comp.), Lecturas sobre pensadores sociales contemporáneos. (pp. 59 - 83). Buenos Aires: Ediciones Del Signo.

Jameson, F. (1991). El posmodernismo o la lógica cultural del capitalismo avanzado. Barcelona: Paidós.

Hernández, I. (Comp.). (2003). Estética de la habitabilidad y nuevas tecnologías. Bogotá: Centro Editorial Javeriano.

Koolhaas, R. (2007). Espacio Basura. Barcelona: Gustavo Gili. 
Lewkowicz I. y Sztulwark, P. (2003). Arquitectura plus de sentido. Buenos Aires: Editorial Altamira.

Mejía, M. (2007). Del discurso de vivienda al espacio residencia. Medellín: Escuela Del Hábitat Cehap, Universidad Nacional De Colombia.

Reyro, C. (2008). Observadores: estudiosos, aficionados y turistas dentro del cuadro. Barcelona: Universitat Autònoma De Barcelona.

Sztulwark, P. (2006). Formas de habitar, formas de vivir. En Sarquis, J. (Comp.), Arquitectura y modos de habitar. (pp. 109 - 122). Buenos Aires: Editorial Nobuko.

\section{Notas}

1. Mejía, Mónica, 2007, 29

2. Hernández, Iliana, 2003, 13 y 17

3. Reyro, Carlos, 2008, 142

4. Cruz, Julio, 2001, 824

5. Hayes, Richard. The Yale Building Project. The First 40 years. Yale University Press, 2007

6. Para más información diríjase a http://www.architecture.yale.edu/drupal/student_work/ building_project

7. Bartra, Roger, 2008, 13

8. Beck, Ulrich y Elisabeth Beck- Gernsheim, 2003, 204

9. De Solà- Morales, Ignasi, 2003, 63

10. Ídem, 119

11. Danto, Arthur. $1999,34-35$

12. De Solà- Morales, Ignasi, 2003, 152

13. Eisenman, Peter. 2011, 10

14. Ídem.

15. Lewkowicz Ignacio y Sztulwark, Pablo, 2003, 52

16. Jameson, Fredric, $1991,87,88$

17. Sztulwark, Pablo, 2006, 115 
